\title{
Traffic related exposures and lung function in adults
}

\section{Fernando Holguin}

\section{Are women more susceptible?}

I is widely known that exposure to outdoor air pollution is associated with acute and chronic changes in expiratory lung volumes. However, most of these studies have assessed exposure to air pollutants using monitors that primarily measure background levels. While this method may be useful in estimating exposure to ozone, it may not provide an adequate estimate of exposure to other pollutants that display small area spatial variations such as ultrafine particulate matter, elemental carbon, polycyclic aromatic hydrocarbons and nitrogen dioxide. ${ }^{1-5}$ Evidence that there is considerable spatial variability in the concentration of traffic related pollutants has sparked interest in assessing the health effects associated with vehicular emissions. Several studies have found that exposure to traffic related emissions are associated with higher rates of adverse respiratory health outcomes including increased respiratory symptoms, ${ }^{6}$ reduced lung expiratory volumes, ${ }^{7}$ increased airway inflammation $^{8}$ and higher rates of healthcare utilisation. ${ }^{9}$ This phenomenon may be partly explained by the properties of the pollutant mix near vehicular emission sources such as a larger concentration of fine and ultrafine particles and higher carbon monoxide and nitrogen dioxide levels. ${ }^{10}{ }^{11}$ What level of proximity to vehicular emissions is associated with adverse health effects? Is there a boundary between exposure to vehicular emissions and background levels? Is there a traffic density threshold associated with health effects? Answers to these and other important questions are unknown, although most studies have found that the rate of adverse respiratory health effects appear to increase proportionately in relation to road proximity and with increasing traffic density. ${ }^{12}$ However, whether or not close proximity exposure to vehicular emissions is more harmful than background air pollutants remains controversial as several studies have failed to show significant associations. ${ }^{13-15}$

In this issue of Thorax Kan et $a l^{16}$ evaluated the association between traffic related exposures and changes in exhaled lung volumes in participants from the Atherosclerosis Risk in Communities (ARIC) cohort study, which included 13972 subjects from four US counties with a mean (SD) age of 54.2 (5.8) years (see page 873). Lung function measures were obtained during visit 1 (1987-9) and visit 2 (2000). To determine traffic exposure, researchers used a geographic information system (GIS) to geocode the residential address of each participant and determined the distance to the nearest road (including road type) and traffic density using a decay function that approximates the potential influence of activity weighted mobile source emissions at varying distances from a roadway. The use of GIS related traffic variables to determine spatial variability of air pollutants has been validated in several studies. ${ }^{17} 18$ Traffic density estimates were directly available for the year 2000 but were extrapolated for years 1987-92 using changes in population density. Exposure to background air pollutants was estimated by interpolating the distance of each participant's residence to the corresponding Environmental Protection Agency monitoring stations.

Based on a positive interaction term between sex and traffic exposures, the authors presented their results in a stratified analysis. In women there was a significant trend for reduced forced expiratory volume in $1 \mathrm{~s}\left(\mathrm{FEV}_{1}\right)$ and forced vital capacity (FVC) with increasing quartiles of traffic density. Women who resided within $150 \mathrm{~m}$ of a major road were also more likely to have reduced $\mathrm{FEV}_{1}$ and FVC. No significant associations were observed in men. Modification of the association between traffic exposures and lung function by sex has not previously been described.

Several explanations could be offered to account for this unexpected finding. First, it could be that women are in fact more susceptible. Although there is no direct evidence to support this assertion, one study showed that women had more severe respiratory symptoms then men when exposed to air pollution from burning agricultural residue. ${ }^{19}$ Several studies have found that women may be more susceptible to the respiratory effects of cigarette smoke. ${ }^{20}$ Further, in population studies of bronchial hyperresponsiveness, women exhibit a greater response to methacholine than men even when adjusting for sex differences in lung volume sizes. ${ }^{21}$

A second possibility may be related to different patterns of residential exposure to vehicular emissions. Because the study evaluated the exposure to traffic at the residence level and a larger proportion of women were more likely to stay at home, it is possible that exposure misclassification in men could account for the lack of significant associations in this group.

Finally, the possibility for residual confounding is a significant concern, especially in cross-sectional studies evaluating exposure to vehicular traffic emissions. Lower socioeconomic position has been associated with road proximity (it was also in this study) and with increased vulnerability to the effects of air pollutants. ${ }^{22}$ Although the trend of traffic density quartiles and lung function remained significant after adjusting for confounders, the individual beta coefficients in each quartile of traffic density were attenuated. Furthermore, the multivariable models of the association between proximity to major roads and $\mathrm{FEV}_{1}$ and FVC were not significant. These results are evidence of the important influence of confounding by socioeconomic position in cross-sectional studies that use traffic related measures as the exposure.

In summary, using traffic density and road proximity as proxy measures of exposure, Kan et $a l^{16}$ have shown that vehicular emissions are associated with chronic lung function changes in a large sample of adult subjects. A study of this magnitude, evaluating the respiratory effects of traffic related exposures in adults, has not been done previously and is a welcome addition to the field. Whether or not women are more susceptible remains to be elucidated and should be determined in a longitudinal study.

Thorax 2007;62:837-838.

doi: $10.1136 /$ thx.2007.078410

Correspondence to: Dr Fernando Holguin, Division of Pulmonary, Allergy, and Critical Care Medicine, Emory University School of Medicine, Davis-Fisher Building, 550 Peachtree Street, NE, 2nd Floor, Room 2331, Atlanta, Georgia 30308, USA; fch5@cdc.gov

Competing interests: None.

\section{REFERENCES}

1 Buckeridge DL, Glazier R, Harvey BJ, et al. Effect of motor vehicle emissions on respiratory health in an urban area. Environ Health Perspect 2002;110:293-300. 
2 Zhu Y, Hinds WC, Kim S, et al. Concentration and size distribution of ultrafine particles near a major highway. J Air Waste Manag Assoc 2002; 52:1032-42.

3 Jamriska $M$, Thomas S, Morawska L, et al. Relation between indoor and outdoor exposure to fine particles near a busy arterial road. Indoor Air 1999;9:75-84.

4 Kinney PL, Aggarwal M, Northridge ME, et al. Airborne concentrations of PM(2.5) and diesel exhaust particles on Harlem sidewalks: a community-based pilot study. Environ Health Perspect 2000;108:213-8.

5 Nielsen T, Jorgensen HE, Larsen JC, et al. City air pollution of polycyclic aromatic hydrocarbons and other mutagens: occurrence, sources and health effects. Sci Total Environ 1996;189-190:41-9.

6 Van Vliet P, Knape M, de Hartog J, et al. Motor vehicle exhaust and chronic respiratory symptoms in children living near freeways. Environ Res 1997:74:122-32.

7 Gauderman WJ, Vora H, McConnell R, et al. Effect of exposure to traffic on lung development from 10 to 18 years of age: a cohort study. Lancet 2007;369:571-7

8 Delfino RJ, Staimer N, Gillen D, et al. Personal and ambient air pollution is associated with increased exhaled nitric oxide in children with asthma. Environ Health Perspect 2006; 1 14:1736-43.
9 English P, Neutra R, Scalf R, et al. Examining associations between childhood asthma and traffic flow using a geographic information system Environ Health Perspect 1999;107:761-7.

10 Reponen T, Grinshpun SA, Trakumas S, et al. Concentration gradient patterns of aerosol particles near interstate highways in the Greater Cincinnat airshed. J Environ Monit 2003:5:557-62.

11 Sahsuvaroglu T, Arain A, Kanaroglou P, et al. A land use regression model for predicting ambient concentrations of nitrogen dioxide in Hamilton, Ontario, Canada. J Air Waste Manag Assoc 2006:56:1059-69.

12 McConnell R, Berhane K, Yao L, et al. Traffic, susceptibility, and childhood asthma. Environ Health Perspect 2006; 114:766-72.

13 Lewis SA, Antoniak M, Venn AJ, et al. Secondhand smoke, dietary fruit intake, road traffic exposures, and the prevalence of asthma: a cross-sectional study in young children. Am J Epidemiol 2005; 161:406-11.

14 Venn A, Lewis S, Cooper M, et al. Local road traffic activity and the prevalence, severity, and persistence of wheeze in school children: combined cross sectional and longitudinal study. Occup Environ Med 2000;57:152-8.

15 Wilkinson P, Elliott P, Grundy C, et al. Case-control study of hospital admission with asthma in children aged 5-14 years: relation with road traffic in north west London. Thorax 1999:54:1070-4.

16 Kan H, Heiss G, Rose KM, et al. Traffic exposure and lung function in adults: the Atherosclerosis Risk in Communities study. Thorax 2007;62:873-9.

17 Henderson SB, Beckerman B, Jerrett $M$, et al. Application of land use regression to estimate longterm concentrations of traffic-related nitrogen oxides and fine particulate matter. Environ Sci Technol 2007;41:2422-8.

18 Jerrett M, Arain MA, Kanaroglou P, et al. Modeling the intraurban variability of ambient traffic pollution in Toronto, Canada. J Toxicol Environ Health A 2007;70:200-12.

19 Long W, Tate RB, Neuman M, et al. Respiratory symptoms in a susceptible population due to burning of agricultural residue. Chest 1998;113:351-7.

20 Anto JM, Vermeire P, Vestbo J, et al. Epidemiology of chronic obstructive pulmonary disease. Eur Respir J 2001;17:982-94.

21 Leynaert B, Bousquet J, Henry C, et al. Is bronchial hyperresponsiveness more frequent in women than in men? A population-based study. Am J Respir Crit Care Med 1997; 156:1413-20.

22 O'Neill MS, Jerrett M, Kawachi I, et al. Health, wealth, and air pollution: advancing theory and methods. Environ Health Perspect 2003;111:1861-70.

\section{Where there's smoke there's lung disease}

\section{Youcheng Liu}

\section{Exposure to biofuels in China}

A lthough global energy consumption from biomass fuels or biofuels is only a small part of the total (12\%), the use is much more prevalent in developing countries than in developed countries (33\% vs 3\%). ${ }^{1}$ It is estimated that almost 3 billion people or $50 \%$ of households worldwide use biomass and coal as their main source of energy for cooking, heating and other household needs. ${ }^{23}$ Biofuels have higher emission factors for particulate matter and other pollutants, especially during incomplete combustion at lower temperatures, ${ }^{4}$ which generates indoor airborne particles at levels much higher than those for cleaner fuels ${ }^{5}$ or outdoors, ${ }^{3}$ and well above levels in most polluted cities. ${ }^{6}$ Such particles also have small aerodynamic diameters (ranging from 0.05 to $1 \mu \mathrm{m}$ for wood smoke, for example) ${ }^{1}$ and can penetrate deep into the alveolar region to induce adverse pulmonary effects. Some of the earliest work concerned with respiratory health and the burning of biofuels in developing countries started with investigations into wood smoke exposure in the 1960s in Papua New Guinea. ${ }^{178}$ More studies on domestic smoke pollution and chronic bronchitis were conducted in rural Nepal. ${ }^{9}{ }^{10}$ In the past two decades a number of epidemiological studies have been conducted specifically to evaluate the burning of solid biofuels as a risk factor for chronic obstructive pulmonary disease (COPD). These studies, performed in various regions of the developing world such as Saudi Arabia, ${ }^{11}$ Columbia, ${ }^{12}$ Mexico, ${ }^{13}$ Turkey $^{14}$ and Nepal, ${ }^{5}$ have shown a link between biofuel cooking and COPD in women. In addition, a link has also been found in developed countries. ${ }^{15}$ Little has been reported, however, on health impacts in general ${ }^{16}$ - and the risk of COPD in particular ${ }^{17}$ - of biofuel indoor air pollution in rural China. A recent large study from rural China showed a significant decrease in reported history of COPD and other respiratory ailments in biofuel and improved stove users compared with coal and traditional stove types. ${ }^{18}$

In this issue of Thorax Liu et al ${ }^{19}$ report a large-scale COPD prevalence study conducted in rural south China and provide further evidence to support the hypothesis that burning of biofuels is a risk factor for COPD in women in rural communities (see page 889). The authors show that the prevalence of COPD was significantly higher in the rural community as a whole-and in non-smoking women in particular-than in the urban community. This was true even after controlling for other risk factors such as smoking status, history of family respiratory diseases and childhood cough, sex, age group, body mass index (BMI) and social economic status (defined by family income). Biofuels, including agricultural crop residuals and firewood, were the main fuel type used in this community and cooking was done in a poorly ventilated kitchen area with inefficient traditional stoves. Environmental measurements showed significantly higher concentrations of sulfur dioxide $\left(\mathrm{SO}_{2}\right)$, carbon monoxide (CO), particulate matter with aerodynamic diameter $<10 \mu \mathrm{m}$ $\left(\mathrm{PM}_{10}\right)$ and nitrogen dioxide in rural kitchen areas using biofuels than in urban kitchens using liquid petroleum gas (LPG).

This study improves our understanding of the risk of COPD in the context of a whole array of other possible COPD risk factors and in comparison with earlier studies which had smaller sample sizes from the community ${ }^{14}$ or were based on hospital patient data. ${ }^{11-13}$ The study by Liu et al has a much larger sample size and is based on random cluster sampling from large populations which provides a more representative sample. Exposure assessments in earlier studies were based on questionnaires with $\mathrm{no}^{11-14}$ or limited number of pollutants measured (mostly $\mathrm{PM}_{10}$ and $\left.\mathrm{CO}\right) .^{5}$ In addition, some of these studies were of a case-control design where exposure assessments using questionnaires may be subject to recall bias and possible exposure misclassifications. Liu et $a l^{19}$ monitored in real time multiple 